\title{
Inovasi Disruptif di Industri Perhotelan
}

by

\section{Bayudin}

Universitas Pendidikan Nasional

info.bayudin@gmail.com

\begin{abstract}
The concept of a market provider of room rentals or residential units using online networking information technology systems such as those conducted by the Airbnb company is now a new competitive concept in the hotel industry. It is still unclear whether it is considered a threat or not in the development of the hotel industry. The purpose of this study is to analyze the concept of online market place whether it is a disruption to the hotel industry and to analyze the reaction of incumbent companies and government policies in addressing the development of the hotel industry. This research used qualitative method that is constructive with literature review and documentation as the premier data source. The results of the study cover the advantages and disadvantages of the existence of online market places for the hotel industry. This research contributes to the hotel industry that the presence of Airbnb companies as an online market place provider is not a nuisance for incumbent companies in the hotel industry. However, standardization of the quality of rooms or residences that are leased needs to be done to ensure the quality of the products and services offered at online market place. Further studies can be conducted to analyze the application of policies for minimum rental rates for rooms offered both by online market-place provider companies such as Airbnb and incumbent companies in the hotel industry.
\end{abstract}

Keywords: Disruption, Inovasi Disruptif, Online Market-place, 


\section{ABSTRAK}

Konsep penyedia pasar penyewaan kamar atau unit hunian dengan menggunakan sistem teknologi informasi jejaring online seperti yang dilakukan oleh perusahan Airbnb kini menjadi konsep jenis binis baru yang bersaingan dalam di industri perhotelan. Hal ini masih belum jelas apakah dianggap sebagai pengganggu atau bukan dalam perkembangan industri perhotelan. Tujuan penelitian ini adalah untuk menganalisis konsep online market-place apakah menjadi gangguan bagi industri perhotelan atau tidak dan di sisi lain menganalisis reaksi perusahaan incumbent serta kebijakan pemerintah dalam menyikapi perkembangan industri perhotelan. Metode penulisan yaitu kualitatif bersifat konstruktif dengan kajian pustaka dan dokumentasi sebagai sumber data premier. Hasil penelitian mencangkup keuntungan dan kelemahan keberadaan online market-place bagi industri perhotelan. Penelitian ini memberikan kontribusi bagi indutri perhotelan bahwa keberadaan perusahaan Airbnb sebagai penyedia online marketplace tidak menjadi gangguan bagi perusahaan incumbent di industri perhotelan. Akan tetapi, standarisasi kualitas kamar atau hunian yang disewakan perlu dilakukan untuk menjamin kualitas produk dan layanan yang ditawarkan di online market-place. Studi lebih lanjut dapat dilakukan untuk menganalisis penerapan kebijakan harga sewa minimum untuk kamar yang di tawarkan baik oleh perusahaan penyedia online market-place seperti Airbnb maupun perusahaan incumbent di industri perhotelan.

\section{Keywords: Disruption, Inovasi Disruptif, Online Market-place}




\section{Pendahuluan}

Dewasa ini industri perhotelan bukan hanya sebuah bisnis yang menawarkan suatu jenis akomodasi yang mempergunakan sebagian atau seluruh bangunannya untuk menyediakan jasa penginapan yang dikelola secara komersial (Darma, 2018). Ragam jenis hotelnyapun sudah sangat berfariasi, bahkan setelah terjadi pembaharuan dalam sistem teknologi informasi, muncul pendatang baru dalam dunia bisnis perhotelan yang melakukan kegiatan bisnisnya dengan inovasi yang berbeda, dengan apa yang telah dilakukan oleh para pelaku bisnis lama sebelumnya. Para pendatang baru tersebut bersaing dalam indutri perhotelan dengan inovasiinovasi yang baru dan inovasi yang dilakukan oleh pendatang baru dirasa mengganggu oleh para incumbent di industri perhotelan (Darma, 2019; Istikhomah dan Darma (2016); Darma dkk (2019).

Menurut Dewi dan Darma (2019) inovasi yang mengganggu merupakan bentuk gangguan oleh pendatang baru, pendatang baru tersebut berkompetisi dengan perusahaan incumbent yang sudah mapan. Inovasi yang mengganggu tersebut digambarkan dengan sebuah kemampuan untuk memanfaatkan sesuatu yang baru dalam satu lini. Sedangkan Agung dan Darma (2019); Putra dan Darma (2019) mengungkapkan bahwa lini yang dimanfaatkan dalam inovasi ini adalah lini terendah yakni para pelanggan yang cepat mendapatkan rasa kepuasan. Sedangkan lini tertinggi dalam hal ini digambarkan dengan pelanggan yang memiliki tuntutan yang tinggi. Distribusi pelanggan ini yang secara median dapat diambil sebagai garis putus-putus untuk menerapkan teknologi baru. Ditambahkan pula Darma (2018) dan Hamid (2017) bahwa inovasi dikatakan sebagai hal yang mengganggu jika inovasi tersebut membawa teknologi baru yang lebih murah dan memudahkan dibanding teknologi sebelumya. Efisiensi yang ditawarkan karena harga yang murah akhirnya mengganggu teknologi lama yang mahal dan tidak efisien. Pemahaman kedua mengenai inovasi yang mengganggu ini apabila terjadi pada industri yang sama. Jika inovasi yang dilakukan tidak membuat pelaku industri lama terganggu atau di lain pihak secara tidak langsung mengganggu industri lain, maka inovasi tersebut tidak dapat dikatakan sebagai inovasi yang mengganggu.

Inovasi disruptif bukan saja datang mengganggu, menghancurkan dan menggantikan teknologi lama. Keberhasilan incumbent dalam melakukan pesaingan menghadapi serangan para pelaku usaha bisnis baru tidak ada jaminan dapat bertahan untuk waktu yang panjang. Kasali (2017) ; Giovanna dan Darma (2019) mengungkapan bahwa ada enam perangkap, pertama success trap atau complacency trap, perangkap yang datang dari keberhasilan pada masa lalu. Success trap adalah satu dari enam perangkap yang terlihat sangat mengemuka pada era disruption sekarang ini. Lima perangkap lainnya adalah the competency trap, the sunk-cost 
trap, the blame trap, the cannibalization trap dan the confirmation trap. Pengusaha yang telah mapan seharusnya menyadari bahwa adanya globalisasi dan modernisasi. Menurut Hamid (2017) keberadaan inovasi yang mengganggu di Indonesia adalah sebuah keniscayaan. Berbagai konflik muncul karena adanya inovasi yang mengganggu ini dan berujung pada kekerasan. Peran pemerintah sebagai regulator tentunya sangat diperlukan untuk menemukan solusi melalui konsolidasi.

\section{Telaah Pustaka dan Kerangka Teoretis}

Landasan teori digunakan untuk membangun kerangka teoretis. Lensa teoretis dalam penilitian ini yakni, disruptive innovation. Definisi disruptive innovation: berasal dari teori dalam bahasa inggris yakni, dalam bahasa Indonesia yang disadur bebas berarti inovasi yang mengganggu.

Menurut para ahli, disruptive innovation adalah sebagai berikut:

A. Menurut King \& Baatartogtokh (2015) dan hasil penelitian dari Widana dan Darma (2018) bahwa terdapat empat elemen utama teori inovasi yang mengganggu: Sebelum mensurvei dan mewawancarai para ahli pada masing-masing dari 77 kasus, diidentifikasi empat elemen kunci dari teori gangguan:

1. Bahwa pemain lama di pasar meningkat sepanjang lintasan mempertahankan inovasi.

2. Bahwa pemain lama melampaui kebutuhan pelanggan.

3. Bahwa pemain lama memiliki kemampuan untuk menanggapi ancaman yang mengganggu.

4. Bahwa para pemegang jabatan berakhir dengan kegagapan sebagai akibat dari gangguan tersebut. Para petahana meningkat sepanjang lintasan inovasi. Dalam The Innovator's Solution, Christensen dan Raynor berpendapat bahwa salah satu elemen kunci dari disruptive innovation adalah sebagai berikut:

1) Di setiap pasar terdapat lintasan perbaikan yang sangat berbeda yang diberikan perusahaan-perusahaan inovasi ketika perusahaan tersebut memperkenalkan produkproduk baru dan lebih baik.

2) Peningkatan bisnis petahana hasil lintasan dari apa yang disebut mempertahankan inovasi.

3) Perbaikan tahun-demi-tahun yang semua perusahaan baik menggilas. Biasanya, inovasi penopang meningkatkan produk di beberapa area nilai yang ditetapkan. Sebagai contoh, perusahaan mobil dapat terus meningkatkan tenaga kuda atau torsi mesin. 
4) Kecepatan mempertahankan inovasi melampaui kebutuhan pelanggan. Elemen kedua dari teori Christensen dan Raynor adalah bahwa laju mempertahankan inovasi di sepanjang lintasan proposisi nilai tertentu.

5) Para petahana memiliki kemampuan untuk menanggapi tetapi gagal mengeksploitasinya.

6) Christensen menulis bahwa tujuan penelitian aslinya adalah pengembangan "kerangka kegagalan" untuk mengapa dan dalam keadaan apa teknologi baru telah menyebabkan perusahaan-perusahaan besar gagal.

B. Menurut Johnshon (2015) disruptive innovation adalah istilah yang diciptakan oleh Christensen, untuk menggambarkan suatu inovasi di ujung bawah pasar yang akhirnya menjungkirkan industri. Menurut Teori Christensen, para pengganggu mengamankan pijakan awal di ujung pasar yang rendah, menawarkan produk-produk yang lebih rendah dan margin yang lebih rendah, misalnya: ketika Toyota memasuki pasar AS pada sekitar tahun 1950, Toyota memperkenalkan Corona, mobil kecil, murahan, tanpa menawarkan embel-embel yang menarik pada pembeli beli mobil pertama kali dengan harga yang rendah.

C. Menurut Christensen, Clayton M., Raynor, Michael and McDonald (2015) inovasi yang mengganggu pertama kali dipopulerkan dengan istilah teknologi yang mengganggu. Christensen memperkenalkan inovasi yang mengganggu sebagai bentuk gangguan oleh pendatang baru, pendatang baru tersebut berkompetisi dengan perusahaan incumbent yang sudah mapan.

Model Inovasi yang Mengganggu

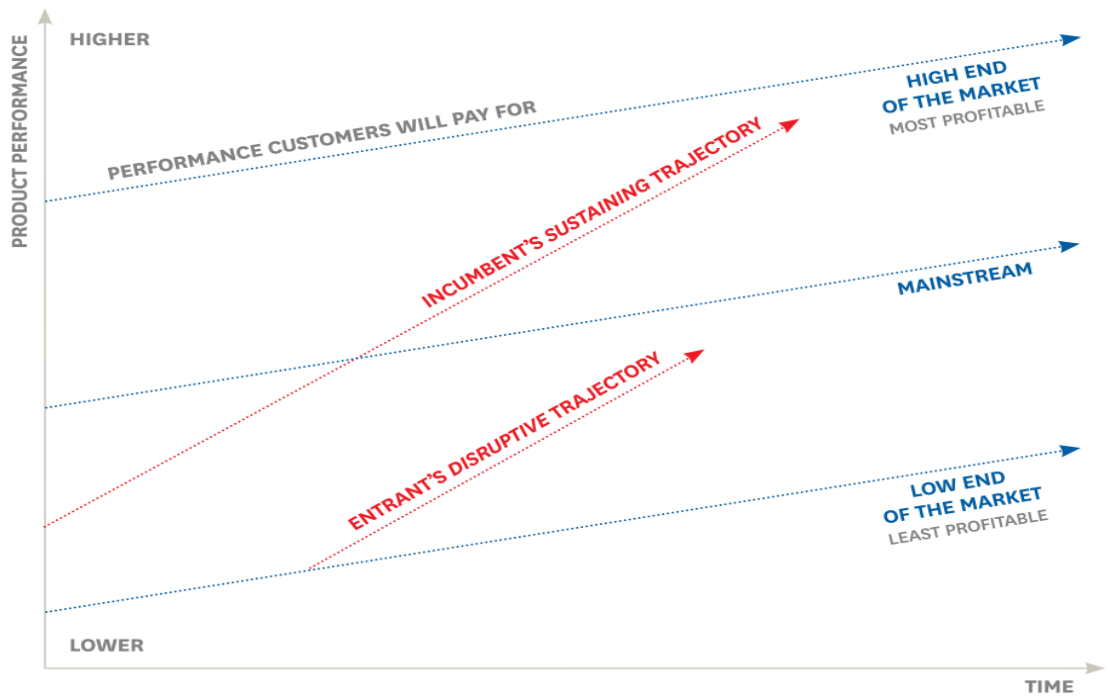

Sumber: Christensen, Clayton M., Raynor, Michael and McDonald (2015) 
Dalam teori persaingan pasar, dikenal structure, conduct, performance (SCP). Datangnya pesaing baru yang membawa teknologi yang mengganggu, tentu akan merubah SCP dalam skala besar. Struktur pasar akan berubah sedikit demi sedikit. Pergeseran akan terjadi menuju industri jasa yang menawarkan kemudahan dan kemurahan. Selanjutnya, conduct yang dipengaruhi oleh konsumen mulai bergeser sesuai dengan kemampuan konsumen untuk mengakses teknologi. Terakhir performance yang dilakukan pasti akan menyesuaikan bagaimana pasar membentuk titik keseimbangan. Teknologi yang mengganggu yang kemudian menjadi inovasi yang mengganggu muncul bukan karena tidak disengaja. Inovasi yang mengganggu muncul sebagai jawaban atas penggunaan teknologi terbaru untuk bisnis. Dengan kata lain, perkembangan pasar akan memaksa SCP dalam industri untuk berubah guna memenuhi kebutuhan konsumen sesuai dengan arus modernisasi.

D. Disruptive innovation adalah sebuah inovasi yang akan menggantikan seluruh sistem lama dengan cara-cara baru. Disruptive innovation akan menggantikan pemain-pemain lama incumbent dengan pemain yang baru. Selain itu, disruptive innovation dapat menggantikan teknologi lama, dengan teknologi digital yang menghasilkan sesuatu yang benar-benar baru. Tentu ada pengecualian, pengecualian itu terjadi bila anda benar-benar cerdik berinovasi, me-reshape model bisnis dengan cara-cara baru, pengecualian itu juga terjadi apabila para elit dan masyarakatnya mau me-reshape undang-undang atau peraturan lama atau memberi ruang sedikit lebih leluasa pada pembaharuan. Inovasi memang sejatinya destruktif atau kreatif, karena itu selalu ada yang hilang, memudar lalu mati. Semua ini menakutkan sekaligus membentengi diri secara berlebihan. Di sisi lain ada hal baru yang hidup. Meski ada lapangan kerja yang hilang, selalu ada yang menggantikannya yang membutuhkan kreativitas, semangat kewirausahaan dan caracara baru, begitulah siklus alam (Kasali, 2017; Dewi dan Darma, 2019; Adnyana dan Darma, 2015; Darma, 2019; Agung dan Darma, 2019; Darma, 2018).

E. Menurut penelitian-penelitian yang telah dilakukan oleh peneliti sebelumnya industri perhotelan mengalami inovasi disruptif. Penemuan penelitan yang berkaitan dengan persoalan tersebut diuraikan sebagai berikut:

1. Penelitian Wiastuti \& Susilowardhani (2016) dengan judul penelitian, Virtual Hotel Operator; is it disruption for hotel industry? Dengan Metode penelitian yaitu kualitatif exploratif, dengan kajian pustaka dan dokumentasi sebagai sumber data primer, keterbatasan jurnal terkait menjadikan berita dan artikel sebagai sumber data sekunder. Dalam penelitian tersebut Virtual Hotel Operator (VHO) yang dijadikan 
objek penelitian yakni, Airy Rooms, RedDoorz, Zen Rooms dan Tinggal. Didapatkan penemuan yang menyatakan bahwa:

1) Keberadaan VHO tidak menjadi faktor pengganggu pada industri perhotelan.

2) VHO pasti meningkatkan kualitas produk, menciptakan lebih banyak nilai ditambahkan, harga kompetitif, membuatnya dapat diakses melalui banyak saluran, menyediakan akses mudah untuk pembayaran dan sistem pemesanan, menjadikannya sebagai terbuka forum untuk peninjauan dan kesaksian.

2. Penelitian Guttentag (2017) dengan judul penelitian Assessing Airbnb as a disruptive innovation relative to hotels: Substitution and comparative performance expectations. Penelitan tersebut dilakukan dengan metode penelitian kuantitatif. Dalam penelitian tersebut didapati temuan sebagai berikut:

1) Banyak tamu Airbnb menggunakan layanan ini sebagai pengganti hotel, dan menunjukkan bahwa tamu Airbnb memiliki harapan yang tinggi terhadap layanan tersebut.

2) Konsep inovasi Airbnd merupakan inovasi yang mengganggu.

3. Penelitian Prabawa (2017) dengan judul penelitian, online marketplace dan tourist virtual communities di industri pariwisata (inovasi disruptive dalam industri pariwisata) penelitan tersebut dilakukan dengan metode penelitian kualitatif. Dalam penelitian tersebut didapati temuan sebagai berikut:

1) Fenomena online marketplace dan tourist virtual communities tidak dapat dihindari dan telah terjadi sebelumnya di negara-negara maju, inovasi telah mengganggu produk yang mendominasi untuk waktu yang lama namun inovasi ini telah mengangkat industri baru dengan manfaat yang tidak dapat diremehkan bagi masyarakat.

2) Perkembangan, kretifitas dan inovasi yang didukung melalui pemanfaatan TIK dalam konteks kepariwisataan global telah melahirkan pasar baru yang memiliki ketertarikan dan minat terhadap produk tertentu yang bersifat resiprokal. 
Kerangka konseptual penelitian digambarkan dalam gambar sebagai berikut:

Kerangka Konseptual

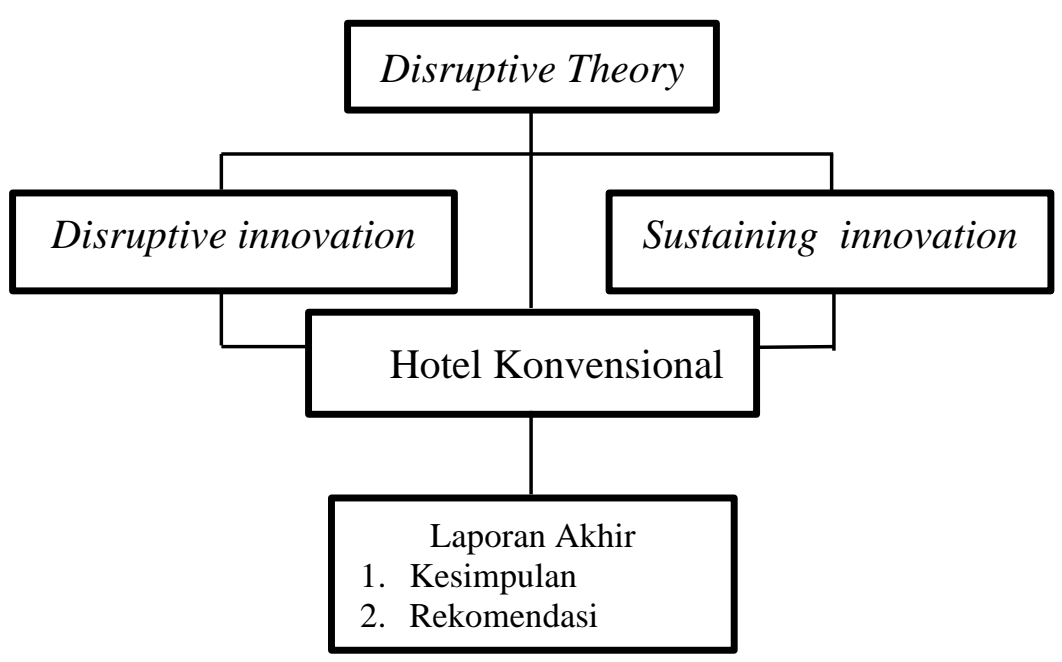

Dalam kerangka konseptual menggambarkan bahwa, penelitian bertujuan untuk meneliti fenomena mengenai inovasi disruptif di industri perhotelan dan hasil dari penelitian akan menyimpulakan relevansi teori disruptive sesuai dengan fenomena yang terjadi di indutri perhotelan. Di sisi lain, hasil penelitian akan memberikan rekomendasi bagi incumbent hotel konvensional dalam menentukan inovasi di industri perhotelan.

\section{Metode Penelitian}

Desain penelitian yang digunakan adalah metode kualitatif bersifat konstruktif. Penelitaian ini akan dilakukan mengetahui reaksi para pelaku bisnis hotel konvensional dan kebijakan pemerintah dalam menanggapi inovasi disruptif di industri perhotelan. Selain itu, metode kualitatif bersifat konstruktif digunakan atas dasar permasalahan yang diteliti dalam penelitian ini masih belum jelas, holistik, kompleks, dinamis dan penuh makna. Selain itu penelitian dimaksudkan untuk memahami situasi sosial secara mendalam, menemukan pola, hipotesis dan teori. Sumber data yang digunakan adalah data sumber primer yakni dokumen hasil wawancara yang didapatkan di setting penelitian, dokumen hasil wawancara tersebut akan dianalisis untuk mengetahui reaksi para pelaku hotel konvensional dan kebijakan pemerintah mengenai inovasi disruptif di industri perhotelan.

Wawancara dilakukan dengan teknik wawancara semistruk dan informan di tentukan berdasarkan informasi yang ingin daigali dari latar belakang pekerjaan seorang informan yakni dari pihak praktisi dan pemerintahan. Maka, pemilihan informan dilakukan dengan menggunakan teknik purposive sample dengan jenis judgdment sample atau sampel bertujuan secara subjektif. Informan perwakilan dari pihak praktisi yakni dari perusahaan incumbent 
sebagai berikut. 1) Informan Home stay Ganidha Apartement yakni, Pemilik Home stay Ganidha Apartement. 2) Informan hotel bintang satu, yakni Pemilik Hotel Adi Guna. 3) Informan Hotel bintang tiga, yakni General Manager Seminyak Garden. 4) Informan hotel bintang empat, yakni General Manager Hotel Sovereign Bali. 5) Informan hotel bintang lima, yakni Pemilik The Royal Santrian. Selain itu, Informan perwakilan dari perwakilan asosiasi perusahaan perhotelan incumbent dan perwakilan dari piak pemerintahan sebagai berikut. 1) Informan dari Lembaga perhimpunan yakni, Ketua Perhimpunan Hotel dan Restoran Indonesia (PHRI) Denpasar. 2) Informan perwakilan dari sektor pemerintahan yakni, Kepala Bidang Pariwisata Badung. 3) Informan perwakilan dari sektor pemerintahan yakni, Kepala Bidang Pemasaran Badung. 4) Informan perwakilan dari sektor pemerintahan yakni, Kepala Bidang Pemasaran Denpasar.

\section{Temuan Penelitian dan Pembahasan}

Dari hasil proses penelitian yang di lakukan peneliti, dengan cara mewawancarai beberapa informan dari berbagai setting penelitian dan hasil wawancara di jadikan data penelitian yang di tampilkan di bagian-bagian sebelumnya. Maka, di temukan hasil penelitian yang diuraikan sebagai berikut:

1. Perusahaan yang bergerak dengan berbasis sitem teknologi yang menciptakan online market-place baru secara online di industri perhotelan seperti perusahaan Airbnb tidak menjadi gangguan bagi bisnis-bisnis perhotelan sebelumnya yang sudah ada dan menguasai pasar industri perhotelan.

2. Standarisasi kualitas produk kamar dan service yang di sediakan oleh Airbnb perlu di tetapkan untuk menjamin kualitas dan mutu produk yang disewakan.

3. Perusahan Airbnb dan sistem teknologi online dapat membantu dalam mempromosikan industri pariwisata dan industri perhotelan lebih luas.

4. Kesiapan para pelaku bisnis perhotelan perlu di lakukan utuk tetap dapat bersaing dengan para pembisnis perhotelan berbasis online.

5. Peranan pemerintah sangat penting dalam menyiimbangkan persaingan bisnis para pelaku lama incumbent di bisnis perhotelan dengan para pelaku bisnis baru yang berbasis sitem teknologi online.

\section{Online market place tidak mengganggu terhadap industri perhotelan}

Melalui hasil penelitian yang dilakukan peneliti berkatian dengan inovasi disruptif di industri perhotelan, di temukan hasil penelitian yang menyatakan bahwa online marketplace 
seperti perusahaan Airbnb tidak menjadi gangguan terhadap industri perhotelan yang sudah ada dan sudah menguasi pasar industri perhotelan yang sudah ada sebelumnya. Dikarenakan incumbent di indusrtri perhotelan memiliki fokus pasar dan strategi yang berbeda dengan apa yang dilakukan perusahaan penyedia online market place. Di sisi lain, standarisasi kualitas produk seperti kamar, rumah atau unit yang disewakan perlu dilakukan oleh perusahaan penyedia online market place.

\section{Pengaruh Online market place terhadap industri perhotelan}

Online market-place dapat memberikan pengaruh terhadap industri perhotelan. Perngaruh tersebut yakni, keberadaan online market-place seperti perusahaan Airbnb di industri perhotelan akan memberikan dampak simbolis mutalisme bagi para pelaku bisnis perhotelan lama di insdutri perhotelan. Di sisi lain, teknologi yang di miliki oleh perusahaan penyedia online market place seperti Airbnb secara tidak langsung dapat membantu industri pariwisata domestik dalam mempromosikan secara lebih mengglobal.

\section{Kesimpulan}

Di temukan hasil penelitian yang menyimpulkan bahwa online marke-tplace seperti perusahaan Airbnb tidak menjadi gangguan terhadap perushaan incumbent yang sudah ada dan sudah menguasi pasar industri perhotelan sebelumnya. Dikarenakan perusahaan incumbent di industri perhotelan memiliki fokus pasar dan strategi yang berbeda dengan konsep oline market-place. Di sisi lain penelitian ini berkontribusi dalam terori disruptive innovation. Menurut Christensen, Clayton M., Raynor, Michael and McDonald (2015) inovasi yang mengganggu pertama kali dipopulerkan dengan istilah teknologi yang mengganggu. Christensen memperkenalkan inovasi yang mengganggu sebagai bentuk gangguan oleh pendatang baru, pendatang baru tersebut berkompetisi dengan perusahaan incumbent yang sudah mapan. Melalui hasil penelitian yang dilakukan berkatian dengan inovasi disruptif di industri perhotelan, ditemukan hasil penelitian yang menyatakan bahwa keberadaan online market-place seperti perusahaan airbnb yang merupakan perusahaan pendatang baru di industri perhotelan tidak menjadi bentuk gangguan dalam industri perhotelan, meski diketahui perusahaan airbnb tersebut berkompetisi dengan perusahaan incumbent yang sudah mapan di industri perhotelan. Selain itu, kontribusi penelitian bagi praktis yakni, 1) Melakukan kerja sama dengan sistem market share dengan perusahaan online travel agent (OTE) seperti traveloka, booking.com, agoda dan perusahaan OTE lainnya merupakan salah satu pilihan strategi yang dapat dilakukan perusahaan incumbent bisnis perhotelan untuk mendapatkan dan 
memperluas jaringan pasar di industri perhotelan. 2) Terus berinovasi dan memperbaiki kualitas kinerja internal manajemen dan mempersiapkan layanan dengan teknologi yang terbaru yang mempuni. 3) Meningkatkan kualitas produk unit dan fasilitas hotel yang dimiliki dan service yang diberikan agar dapat tetap mempertahankan eksistensi binis dan dapat bersaing dalam persaingan bisnis di industri perhotelan. Sedangkan kontribusi penelitian bagi praktis online market-place yakni, 1) Perlu melakukan standarisasi dalam setiap unit yang disewakan. Standarisasi tersebut dapat berupa kualitas produk dan layanan yang sama halnya telah diterapkan dalam perushaan incumbent yang sudah ada sebelumnya. 2) Menerapkan ketentuan standarisasi ketetapan harga dalam jenis-jenis unit hunian yang disewakan. 3) Bekerjasama dengan peraturan dan pemerintahan setempat dalam industri perhotelan maupun industri pariwisata. Di sisi lain, kontribusi kebijakan dari hasil temuan penelitian yang dapat dijadikan pertimbangan dalam membuat kebijakan yang berkaitan dengan masalah yang berkaitan dengan permasalahan yang diteliti yang berkaitan dengan industri perhotelan. 1) Pemerintahan setempat perlu melakukan standarisasi unit yang disewakan di online marketplace seperti satndarisasi yang telah diterapkan pemerintahan di hotel perusahaan incumbent. 2) Pemerintahan perlu melakukakan pendataan untuk perusahaan yang melakukkan kegiatan operasional perushaan berbasis sistem teknologi informasi jejaring online seperti perusahaan penyedia online market-place yakni Airbnb maupun perusahaan travel agent online seperti perusahaan traveloka, booking.com ataupun perusahaan sejenis yang beropasional di industri perhotelan. 3) Pemerintah perlu melakukan deligasi untuk menjembatani kerjasama yang dilakakukan perusahaan yang berbasis sistem teknologi online maupun perusahaan incumbent di industri perhotelan.

Panduan Untuk Penelitian Mendatang

Peneliti menyadari keterbatasan yang dimiliki penelit, yakni tidak dapat meneliti seluruh masalah yang terjadi di industri perhotelan. Maka peneliti berharap dengan rekomendasi ini, dapat memberikan panduan untuk penelitian mendatang terkait masalah atapun industri yang berkaitan dengan penelitian ini. Penelitian mendatang dapat di lakukan mengenai masalahmasalah yakni 1) Dunia dan sistem teknologi digital akan terus berkembang sesuai dengan waktu dan masa, dan perkembangan tersebut pasti akan memberikan dampak, baik secara umum dalam seluruh lini kehidupan maupun secara khusus yakni di industri perhotelan. Maka penelitian kedepannya perlu dilakukan untuk mengetahui pengaruh perkembangan sistem teknologi informasi digital terhadap industri perhotelan. 2) Belum ada kebijakan atau peraturan di industri perhotelan yang mengatur harga minimum sewa kamar hotel, dan hal tersebut menjadi masalah bagi persaingan bisnis di industri perhotelan. 


\section{Implikasi Penelitian}

Implikasi hasil penelitian bagi industri perhotelan yakni, perusahaan incumbent perlu mempertimbangkan untuk melakukan kerja sama dengan perushaan penyedia online marketplace karena kensep tersebut, bukan merupakan inovasi disruptif di industri perhotelan. 


\section{DAFTAR PUSTAKA}

Agung, N.F.A., and Darma, G.S. (2019). Opportunities and Challenges of Instagram Algorithm in Improving Competitive Advantage, International Journal of Innovative Science and Research Technology, 4 (1): 743-747.

Adnyana, R., and Darma, G.S. (2015). Strategi Marketing Mix, Yield Management, Customer Satisfaction and Occupancy Rate, Jurnal Manajemen \& Bisnis, 12 (1): 92-115.

Bower, J. L., \& Christensen, C. M. (1995). Disruptive Technologies: Catching The Wave, Harvard Business Review, 73 (1): 1-19.

Christensen, C. M., Raynor, M., \& McDonald, R. (2015). What is disruptive innovation?, Harvard Business Review, 93 (12): 44-53.

Darma, G.S. (2019). Kacamata Media, Kesuksesan Bersyarat. Indonesia: Pustaka Larasan Press.

Darma, G.S., Apollo, A., Rusmanda, G., and Umar, Y. (2019). Digital Education 4.0. Indonesia: Cakra Media Utama Press.

Darma, G.S. (2018). Seuntai Pesan, Menjawab Zaman. Indonesia: Pustaka Larasan Press.

Darma, G.S. (2006). The Impact of Information Technology Investment on the Hospitality Industry, Jurnal MAKSI, 6 (1): 1-22.

Darma, G.S. (1999). Information Technology and Organisational Performance: A Study of the Hospitality Industry, Southern Cross University, Lismore New South Wales Australia.

Dewi, M.V.K., and Darma, G.S. (2019). The Role of Marketing \& Competitive Intelligence In Industrial Revolution 4.0, Jurnal Manajemen \& Bisnis, 16 (1): 1-12.

Ferdiana, A.M.K., and Darma, G.S. (2019). Understanding Fintech Through Go-Pay, International Journal of Innovative Science and Research Technology, 4 (2): 257-260.

Giovanna, N., and Darma, G.S. (2019). Scanlated vs. Physical Japanese Comic Manga, International Journal of Innovative Science and Research Technology, 4 (1): 630-636.

Guttentag, D. (2017). Assessing Airbnb as a disruptive innovation relative to hotels: Substitution and comparative performance expectations. ttra International Conference. University of Massachusetts Amherst.

Hamid, E. S. (2017). Disruptive Innovation: Manfaat dan Kekurangan Dalam Konteks Pembangunan Ekonomi, 1-20.

Istikhomah, I., and Darma, G.S. (2016). Masifnya Penggunaan Online Travel Agents Dalam Meningkatkan Revenue Pemasaran, Jurnal Manajemen \& Bisnis, 13 (1): 52-63.

Johnshon, W. (2015). Disrupt Yourself: Putting the Power of Disruptive Innovation to Work. New York: Bibliomotion Inc. 
Kasali, R. (2017). Disruption. Jakarta: PT Gramedia Pustaka Utama.

Kasali, R. (2017). Tomorrow is today (Disruption). Bandung: Mizan Anggota IKAPI.

King, A. A., \& Baatartogtokh, B. (2015). How useful is the theory of disruptive innovation?, MIT Sloan Management Review, 57 (1): 77-90.

Prabawa, I. W. S. W. (2017). Online marketplace dan tourist virtual communities di industri pariwisata (inovasi disruptive dalam industri pariwisata), Jurnal Ilmiah Hospitality Management, 8 (1): 39-46.

Putra, I.G.N.A.P., and Darma, G.S. (2019). Is Bitcoin Accepted in Indonesia?, International Journal of Innovative Science and Research Technology, 4 (2): 424-430.

Saefulloh, D.A., and Darma, G.S. (2014). Strategi Marketing Wisata Wedding Sebagai Destinasi Alternatif, Jurnal Manajemen \& Bisnis, 11 (1): 17-34.

Widana, I.W., and Darma, G.S. (2018). Branding Denpasar Smart City Guna Meningkatkan Kunjungan Wisatawan, Jurnal Manajemen \& Bisnis, 15 (1): 176-199.

Wiastuti, R. D., \& Susilowardhani, E. M. (2016). Virtual Hotel Operator; Is it disruption for hotel industry?, Hospitality Dan Pariwisata, 2 (2): 201-215. 